\title{
On the Prospects \\ of Digitalization of Justice
}

\section{目 Oleg Stepanov}

Chief Researcher, Centre of Criminal Law, Criminal Procedure and Judicial Practice, Institute of Legislation and Comparative Law under the Government of the Russian Federation, Doctor of Juridical Sciences. Address: 34 Bolshaya Cheremushkinskaya Str., Moscow 117218, Russian Federation. E-mail: crim@ izak.ru

\section{目 Denis Pechegin}

Senior Researcher, Centre of Criminal Law, Criminal Procedure and Judicial Practice, Institute of Legislation and Comparative Law under the Government of the Russian Federation, Candidate of Juridical Sciences. Address: 34 Bolshaya Cheremushkinskaya Str., Moscow 117218, Russian Federation. E-mail: crim5@ izak.ru

\section{目 Maria (Dolova) Diakonova}

Senior Researcher, Department of Civil Legislation and Procedure, Institute of Legislation and Comparative Law under the Government of the Russian Federation, Candidate of Juridical Sciences. Address: 34 Bolshaya Cheremushkinskaya Str., Moscow 117218, Russian Federation. E-mail: civil@izak.ru

\section{睢围 Abstract}

The article considers the problem of digitalization of judicial activities in the Russian Federation and abroad. Given the fact that in the modern world elements of digital (electronic) justice are gaining widespread adoption, the article presents an analysis of its fundamental principles and distinguishes between electronic methods of ensuring procedural activity and digitalization of justice as an independent direction of transformation of public relations at the present stage. As a demonstration of the implementation of the first direction, the article presents the experience of foreign countries, Russian legislative approaches and currently being developed legislative initiatives in terms of improving the interaction of participants in the procedure through the use of information technologies. The authors come to the conclusion that the implemented approaches and proposed amendments are intended only to modernize the form of administration of justice with new opportunities to carry out the same actions (identification of persons participating in the case, notification, participation in the court session, etc.) without changing the essential characteristics of the proceedings. The second direction, related to electronic (digital) justice, is highlighted from the point of view of the prospects and risks of using artificial intelligence technologies to make legally significant decisions on the merits. At the same time, the authors argue that the digitalization of justice requires the development and implementation of the category of justice in machine-readable law, as well as special security measures of both technological and legal nature. 


\section{O-1티 Keywords}

digitalization, judicial activity, justice, foreign experience, artificial intelligence, justice.

For citation: Stepanov O.A., Pechegin D.A., Diakonova M.O. (2021) On the Problem of Digitalization of Justice. Legal Issues in the Digital Age, no 2, pp. 104-120.

DOI: $10.17323 / 2713-2749.2021 .2 .104 .120$

\section{Introduction}

According to the Decree of the President of Russia of May 7, 2018 No. 204 "On national goals and strategic objectives of the development of the Russian Federation for the period up to 2024", the process of digitalization of public practice is strategic in nature. The program "Digital Economy of the Russian Federation", among other things, provides for the need to improve the legal regulation of the implementation of state functions.

This trend is typical for most countries. Thus, in accordance with the Recommendations of the Committee of Ministers of the Council of Europe CM / Rec $(2009) 1$ on e-democracy (adopted by the Committee of Ministers on February 18, 2009 at the 1049th meeting of deputy ministers), e-justice is intended to generally improve the efficiency and quality of public services through electronic communication and data exchange; and access to judicial information.

New technologies, on the one hand, are designed to improve the life of society by simplifying access to public services, increase the efficiency of participation in economic turnover, and strengthen economic ties between actors. [Khabrieva T., Chernogor N., 2018: 85-102]. At the same time, by virtue of their technical nature, the technologies are not devoid of shortcomings, the problem modern researchers do not cease to pay attention to [Kucherov I., 2017: 69-79].

Nevertheless, the prospects for the active introduction of artificial intelligence and other digital technologies make it necessary to understand the legal regulation of these processes [Medvedev R., 2018: 14]. In this respect, justice is no exception, because its activities constitute the pivotal basis of rule of law in the state as a whole.

The range of «depth» of digitalization of the procedural form varies from the use of electronic means of communication only as a way to simplify the resolution of the case to the use of the capabilities of $\mathrm{AI}$ as a way to resolve the dispute itself on the merits [Povetkina N., Ledneva Yu., 2018: 46-67]. 
In this regard, in legal science, a distinction is made between the terms «electronic provision of justice» and «electronic justice» [Reshetnyak V., Smagina E., 2017: 16-19].

«Electronic provision of justice» consists in the use of information technology as an «auxiliary means» and is synonymous with the informatization of the court's activities. In this case, we are not talking about a complete replacement of traditional approaches with new ones - involving electronic exchange and analysis of information, but about supplementing the existing mechanisms with auxiliary ones - such as the possibility of submitting procedural documents and evidence to the court in electronic form, electronic notification, participation in court hearings via the web-conferences (without actually appearing at the courthouse), which are used exclusively with the voluntary expression of the will of the party to the dispute.

Electronic (digital) justice, on the contrary, is not limited to the use of technology as a means of simplifying the process, but involves the digitalization of justice from a substantive point of view (including by changing the subjects of the assessment of evidence and making decisions on the case). Since a process is a set of completely definite norms, rules and procedures governing the proceedings on a case, having the necessary data, it is quite possible to predict the specific outcome of any action of one or another participant in the process. Taking this feature into account would allow technical simplification and improvement of citizens' access to justice, including at the pre-trial stages of the proceedings.

In this case, the adoption of legally significant decisions is delegated to AI-technologies: for example, the evaluation by a computer of documents and evidence submitted to the court, the decision on their adoption, the issuance of final judicial acts. At the same time, electronic support of judicial activity, in contrast to electronic (digital) justice, involves the improvement of only the form of legal proceedings, without affecting its substantive part. Since the rapid development of electronic provision of justice in Russian and Western legislation cannot be fully identified with digital justice, which requires an independent model of legal implementation, it is necessary to consider the relationship between electronic provision of justice and electronic (digital) justice in more detail.

\section{Electronic support for administration of justice}

Both Western and Russian legislation is developing towards improving the electronic forms of administration of justice, which implies the implementation of the following main components. 
1. Information transparency of judicial activity is ensured by creation of interactive search engine on the Internet, through which one can obtain information about the structure of the judicial system, the organization of the work of courts, the staff of judges, the legal basis of the activities of the courts, cases pending, etc. Such a system may provide for different levels of access depending on the status of the person: non-participant in the process, a participant in the process, a court employee. For example, in the United States, there is a service «Public Access to Court Electronic Records» (PACER), which allows users to receive information about court cases online from federal courts of appeal, district courts and commercial courts. PACER provides registered users with access to information on court cases; the use of this system is paid ( $\$ 0.10$ per page of document). The federal judicial system itself has a case management / electronic case files (CM / ECF) system, PACER is an interface to this system for public access. The system is decentralized and each court has its own servers and its own copy of the software. Each court has a live server and separate training and test servers. The test server is used to make changes and install new versions before getting started. The learning server allows users to learn how to use CM / ECF without touching real cases. Since 1997, Singapore has been operating a platform for filing documents in courts via the Internet the Electronic Filing System. ${ }^{1}$ The platform provides an electronic register and the entire document management system of the Supreme Court and subordinate courts. In addition, with its help, all documents submitted to the court are automatically checked for compliance with the requirements for this type of documents without involving the human factor. Further routing of the document is also designed automatically.

In Russia, there is currently no unified system of information on judicial activity: for courts of general jurisdiction there is an Internet portal GAS „Pravosudie“ (in English: Justice state information system) (www.sudrf. $\mathrm{ru}$ ), for arbitration courts — the information system „kad.arbitr.ru“.

Further development of technical support for legal proceedings involves the creation of a single portal, which includes a card index of electronic court cases and provides interaction with other state information systems, including the «Integrated Portal of State and Municipal Services» (Rus. Gosuslugi).

2. Notification of interested parties about the course of legal proceedings, as well as interaction between the participants in the process through

${ }^{1}$ Available at: https://www.sicc.gov.sg/forms-and-services/electronic-filing-service (accessed: 01.04.2021) 
the use of electronic means of communication. A problematic element of legal proceedings remains the notification of the persons participating in the case about the initiation of proceedings, the holding of court sessions and the performance of procedural actions. The benefits of informing the parties to the process using the Internet, in terms of speeding up and simplifying the notification process, and reducing human and material costs, are fully recognized by governments that continue to introduce information technology into administration of justice.

As a rule, the law provides for the possibility of submitting any documents to the court in electronic form, as well as the electronic exchange of documents between the parties and the court. Almost everywhere, electronic communication requires the separate consent of the participant in the process. So, in Germany, an electronic document can be sent to the parties to the proceedings if they have expressly agreed to transfer documents electronically (clause (3) $\$ 174$ of the German Civil Procedure Code). Fully electronic communication is established between courts and government agencies and institutions. Secure channels for the transmission of documents have been established: through a specific e-mail; through a special electronic mailbox of a lawyer; through the mail of an authority or a legal entity of public law; through other nationwide transmission channels that guarantee the authenticity and integrity of the data.

The Civil Procedure Rules of England also establish the possibility of sending court documents by electronic means of communication (6.23 (5), 6.23 (6)). Instruction 6A detailing these rules (para 4.1-4.3) specifies that a document can be sent by fax or other electronic means when:

the party (its representative) has previously informed in writing about its readiness to receive notifications by fax or other electronic means and has provided an e-mail address or other electronic identification;

the fax number or e-mail address is indicated on the official documents submitted by the party (its representative).

In this case, if a party intends to serve a document using electronic means (except for facsimile communication), you should first ask the other party if there are any restrictions in the recipient's consent to accept documents by such means. The legislation of the post-Soviet states - Georgia, Kazakhstan, Moldova, Ukraine, Estonia, etc. also contains a number of norms related to the digitalization of legal proceedings.

In the conditions of free will of the parties to the law enforcement process, there is an active use of information exchange between the parties 
through electronic communication, which is explained by their equal interest in the prompt consideration of the case. The approach, in which electronic channels of communication are selected by the parties on their own, seems to be more correct and effective than the imposition of digital technologies by the state authorities.

The practice of electronic legal proceedings is quite widespread within the judicial systems of countries such as Austria, Denmark, Italy, Canada, the Netherlands, Saudi Arabia, Singapore, the US, Sweden, South Korea, etc. In these states, as a rule, the legislative level provides for the possibility submission of any documents to the court in electronic form, as well as the exchange of documents between the parties in electronic form. Almost everywhere, with the exception of Singapore, special consent of the party is required for electronic interaction.

According to Russian law, applications, complaints and other documents can also be submitted to the court in the form of an electronic document signed with an electronic signature or by filling out a form posted on the official website of the court. Electronic methods of notifying the participants in the process are becoming more and more widespread: for example, in the arbitration process, after receiving the initial notification in the traditional form, no subsequent notification is made - the relevant acts are posted on the portal, and the parties can independently familiarize themselves with them. In civil proceedings, such a rule so far only applies to state bodies and organizations, but in the draft laws currently being developed, it is proposed to extend such regulation to citizens. ${ }^{2}$

3. The use of information technology in the proceedings on the merits. Currently, in some Western countries, computer technology and electronic communications are used to better organize the work of courts, to speed up and simplify legal proceedings. To this end, an electronic case management system is being introduced into state courts, which ensures the management of information flows: electronic registration of a case, determination of information about the parties, accounting for incoming and outgoing documents, routing the progress of the case and monitoring procedural deadlines, preparing judicial statistics, ensuring communication with all participants of the process.

2 See e.g. the draft of federal law «On Amendments to the Arbitration Procedure Code, Civil Procedure Code, Code of Administrative Procedure of the Russian Federation» in terms of ensuring the possibility of submitting documents to the court through a single Internet portal of public services, participation in court sessions via videoconferencing. 
Such a platform allows to process and store documents with their registration, optimizing the process of legal proceedings as a whole. In the United States, as mentioned above, this is the Case management / Electronic case files (CM / ECF) system, which has been operating in all federal courts since 2004 .

Currently, automation of certain types of legal proceedings is taking place, in which the simplest, indisputable claims for the collection of small sums of money are resolved. It seems that the automation of the process of making a legally significant decision is possible in those categories of cases where the subject of proof and evidence are predetermined, confirming facts that are important for the case, where the function of the court, in fact, is reduced to confirmation and certification. Such cases, first of all, include cases of writ proceedings. Some legal scholars do not consider the proceedings on the issuance of a writ (a court order) to be justice at all, since there is no adversarial procedural form, as such is the free discretion of the judge, an easy procedure for canceling the issued warrants is provided. Subject to filling out the form on the court's website, attaching the necessary evidence to it, the decision to issue the writ can be made by the program.

For example, in Germany there is an electronic writ proceeding, the introduction of which became possible when maintaining only a formal check of the application for the issuance of a warrant for the admissibility of the requirements. An application for the issuance of a warrant, containing all the necessary conditions and requirements, is filled out in an electronic form posted on the Internet, while the possibility of correcting mistakes is allowed. Re-examination of the application for admissibility is not required. At the same time, any attempts to introduce an AI-system by completely replacing the work of a judge in considering and resolving disputes and conflicts, assessing the evidence presented by the parties can hardly be supported.

The use of videoconferences in court hearings is a generally accepted practice in many countries. However, in common law countries, where jury trials are traditional, videoconferencing is an exceptional way of participating in a trial, since its use does not allow to establish personal contact with a participant in the trial.

It is noteworthy that the technical, in essence, issue of the form of participation in the hearing has an impact on the transformation of the process of proof, which can be demonstrated by the following example. ${ }^{3}$

${ }^{3}$ See: Rudnev V., Pechegin D. The Impact of the Leading Digital Technologies on Criminal Proceedings: A Case of Video Conferencing. 6th International Conference on social, economic, and academic leadership. 2020. DOI: 10.2991/assehr.k.200526.047. 
As a general rule, in proceedings in the International Criminal Court (hereinafter - ICC), testimony is given by witnesses in person at the hearing. ${ }^{4}$ This opens up the opportunity for the parties to publicly and openly interrogate witnesses, find out their answers to questions, present to the court an assessment of the reliability of the witness's testimony, which strengthens the adversarial principles of criminal proceedings in the ICC, and also complies with the rights of the accused under Article 67 (1) (e) of the Rome Statute.

However, pursuant to Article 69 (2) of the Rome Statute and the Rules of Procedure and Evidence, the Trial Chamber of the ICC may order that witness statements that have been recorded previously during a criminal investigation or in court proceedings be reproduced at a hearing. Such a decision can be taken when the witness is unable to testify due to illness, death, injury, age, or in other similar cases, such as a unique opportunity for investigation provided for in Article 56 of the Rome Statute. Or if the issue concerns ensuring the safety of participants in criminal proceedings in accordance with article 68 of the Rome Statute.

In particular, based on the requirements of Article 67 of the Rome Statute, the necessary level of security can be achieved during the interrogation of a witness through videoconferences using technologies to change the witness's voice and demonstrate only his silhouette. Moreover, under certain circumstances, the examination of a witness may be initiated under in camera and ex parte conditions, as indicated by Rule 88 of the Rules of Procedure and Evidence. For example, in order to establish his identity in a court session, but to prevent the possibility of possessing information about his (her) identity by any of the participants in the process.

However, the drafters of the Rome Statute also envisaged imposing on the ICC Trial Chamber the obligation in each case to reproduce the testimony of a witness in his absence, to take into account the potential risks of violation of the rights of the accused by this decision, including while observing the requirements of procedural economy. Thus, there is an obvious desire of the developers of the Rome Statute to lay as its basis the requirement to maintain a balance of interests of all participants in the criminal proceedings, as well as the parties (including the injured party), regardless of the form of organization of the proceedings. In any case, the defendant acquires the right in each such situation to express to the court his attitude

${ }^{4}$ Prosecutor v. Lubanga. ICC Trial Chamber Decision on the Prosecution's application for admission of four documents from the bar table pursuant to Article 64(9). 20 January 2011. ICC-01/04-01/06-2662. Para 13. 
to the testimony presented, as well as to give counter-arguments in favour of his interpretation of the events. In doing so, one must also bear in mind the provisions of Article 64 (6) (b) of the Rome Statute, which provides for the right of the ICC to seek assistance from a particular state in order to ensure the appearance of a person at a court hearing ${ }^{5}$, including through videoconferencing ${ }^{6}$ under Article 93 ( 1) (b) Rome Statute [Broomhall B., 2003: 158], if the interests of the safety and comfort of the witness so require. ${ }^{7}$

With regard to all the ways of presenting the ICC information described above, the experience of its predecessor - the ICTY, which was the first to introduce a gradation of evidence depending on the form of presentation, is very interesting, which was a reflection of the inquisitorial model of constructing the process of proof. Thus, in the case of Prosecutor v. Tadić, the court found that the evidentiary value of the testimony presented by videoconference, although it is more significant than the written testimony, cannot be as significant as the testimony presented in the courtroom in person. This gradation was also adopted within the framework of the regulation of the proof process in the ICC as the successor of international tribunals. ${ }^{8}$ According to the established gradation, the evidence will be assessed differently in the process of considering the case in the ICC on the merits. In other words, when resolving a case, the ICC will most likely give preference to testimony that was presented directly during the trial and, on the contrary, if there is «better» evidence, it will not justify the decision by written testimony not personally confirmed by one or another participant of the trial.

In this refraction of the structure of evidence, we can talk about the revival at the present stage of the idea of classifying evidence by their force, which was inherent in the inquisitorial form of criminal proceedings. And such regulation does not contradict internationally recognized standards

${ }^{5}$ Prosecutor v. Ruto et al. ICC Trial Chamber Decision on Prosecutor's Application for Witness Summonses and resulting Request for State Party Cooperation. 17 April 2014. ICC-01/09-01/11-1274-Corr2. Para 100, 193.

${ }^{6}$ Prosecutor v. Ruto et al. ICC Appeal Chamber Judgment on the appeals of William Samoei Ruto and Mr Joshua Arap Sang against the decision of Trial Chamber V (A) of 17 April 2014 'Decision on Prosecutor's Application for Witness Summonses and resulting Request for State Party Cooperation'. 9 October 2014. ICC-01/09-01/11-1598.

7 Prosecutor v. Bemba. ICC Trial Chamber Public redacted decision on the 'Prosecution request to hear Witness CAR-OTP-PPPP-0036's testimony via video-link' 3 February 2012. ICC-01/05-01/08-2101-Red2. Para 7.

8 Prosecutor v. Tadić. ICTY Trial Chamber II Decision on the Defence Motions to Summon and Protect Defence Witnesses and on the Giving of Evidence via Video-link. 25 June 1996. Case No. IT -94-1. Para 21. 
in the field of criminal proceedings, as well as the requirements of adversariality. On the contrary, the foregoing testifies in favor of the real possibility of combining adversarial and investigative principles, and at a higher level - within the framework of building a digital evidence process and organizing judicial activity.

An essentially new stage in the informatization of the administration of justice is the creation of fully electronic courts. For example, the Hangzhou Internet Court in China, established in August 2017, is one of the first courts in China to consider cases exclusively via the Internet, and it has jurisdiction over intellectual property disputes on the Internet.

The legislative initiatives currently being developed in the following areas are aimed at a wider application of the latest technologies in Russian legal proceedings: remote electronic appeal to the court through the personal account of a participant in the trial; remote receipt of subpoenas and other court notices in the personal account of the participant in the process; remote receipt of judicial acts and their copies in electronic form in the personal account of the participant in the process; the possibility of admitting persons to participate in court sessions through a web conference, without the need to appear in person in court by authenticating the participant using his biometric personal data.

It should be noted that now in Russia, electronic technologies are most actively used in the arbitration process, to a lesser extent in civil, administrative and criminal proceedings, which is largely due to the difference in the technical support of courts of general jurisdiction and arbitration courts, as well as the specifics of the participants in cases considered in these types of courts. In this regard, it seems promising to change the emphasis in legal regulation - the use of traditional means only in cases where there is no technical ability to access electronic means of communication, provided there is a voluntary consent of interested parties to electronic means of interaction.

The indicated implemented approaches and proposed innovations are intended only to modernize the form of administration of justice with new possibilities for carrying out the same actions (identification of persons participating in the case, notification, participation in the court session, etc.) without changing the essential characteristics of the proceedings.

Meanwhile, it should be borne in mind that today a new digital sphere of public relations is being formed, requiring not only the modernization of legislation, but also the adaptation of the judicial system to changing reali- 
ties. Digital justice is fundamentally different from the use of information technology only to improve the form of traditional legal proceedings.

At the same time, we note that the term "digital justice" is more in line with the future vector of development of the state and society. The substantive difference of digital justice is that it will affect not only the modification of the form of legal proceedings, but also the composition of the participants in the process, the rules for assessing evidence, etc. At the same time, analyzing these transformations, it is necessary, first of all, to determine the relationship between the concepts of "digital justice" and "justness" ("fairness").

\section{Problems of ensuring fairness and security of digital justice}

The activities of the state related to the consideration of a case of an offense or a legal dispute determine the content of the jurisdictional function of the authorities, since justice is the most perfect means of legal protection of the interests of the state and the individual [Kuzurmanova I.V., 2011:37-40].

Proceeding from the fact that the main function of the judiciary is to administer justice and the court is called upon to restore the right in case of violation of the law, it is important to consider such power not just as a separate part of the state mechanism, but as the power that confirms the fairness of the state organization of society [Pizzi W., 2016: 212].

Therefore, the digital transformation of the jurisdictional sphere should be aimed at ensuring trust in digital records, as well as establishing an appropriate regime for the collection and storage of digital evidence by programs. Such software solutions should take into account the peculiarities of regulating digital legal relations in legislation and fixing legal facts, which, among other things, will require the development of special rules of procedural evidence.

The digitalization of substantive legal relations lays the foundation for the transformation of the institutions of evidence, for example, in terms of mechanisms for determining the reliability, admissibility and legal force of digital evidence, methods of their assessment by the court, but achievements in the field of electronic forms of judicial proceedings, it seems, will not yet be able to solve the problems of digital evidence due to their attachment to traditional forms of evidence (electronic signature - handwritten signature, written protocol - audio and video recording, etc.). This circumstance is of key importance for ensuring the proper quality of «justice of the future», which should be associated with the increasing role of the 
court in maintaining a balance between individuals, society and the state. At the same time, improving the quality of judicial acts through the use of digital technologies should be considered as a factor determining the formation of this balance. Based on this, at this stage, it is important to define the achievement of digital justice as the basis of «digital» fairness.

Justice (fairness) is a fundamental component of jus naturalis that belongs to a person from his birth. It defines the essence of law and is its basis [Saksonov A., 2016: 37]. The ability of law expresses the idea of fairness (law is a normatively enshrined and realized fairness) and is closely related to the very idea of justice. The great Russian jurist Anatoly Koni pointed out more than a hundred years ago justice cannot be excluded from fairness, i.e. come into conflict with this fundamental position [Isaev I.A., 1994: 51].

The use of digital technologies designed to minimize the influence of the human factor in the process of making legal decisions can have a significant impact on reducing the potential of such a contradiction. At the same time, it is important that any modern digital technology, offering a solution to the merits of the case, is able to test the entire array of previously adopted legally significant decisions, taking into account the fact that the model embedded in them corresponds to the value foundations of justice.

Modern technologies already today most accurately predict the outcome of most cases considered by the courts. Thus, the experience of some private companies that realize the potential of the latest technologies and even AI is of interest. A prime example of this is LexMachina, a predictive litigation platform owned by LexisNexis, and Thomson Reuters' Westlaw Edge platform. This is done by automatically collecting and analyzing information posted on the Internet about court proceedings, judges, lawyers, parties and the cases themselves.

There are striking examples of programs using artificial intelligence, built on deep learning technology, to predict the results of decisions of the European Court of Human Rights. ${ }^{9}$ Having gained access to evidence in a particular case, the technologies assessed them in accordance with the specified parameters with an accuracy of verdicts of about $79 \%$ of 584 cases considered [Aletras N., Tsarapatsanis D., Preoțiuc-Pietro D., 2016: 93].

As a result of a similar American experiment, the researchers developed a special "smart" program, which was tasked with analyzing the judgments

9 Available at: https://www.independent.co.uk/life-style/gadgets-and-tech/news/ ai-judge-robot-european-court-of-human-rights-law-verdicts-artificial-intelligence-a7377351.html (accessed: 07.07.2020) 
of the US Supreme Court for the period from 1816 to 2015 through specific algorithms. The program found a connection between the circumstances of cases and the decisions made on them and accurately predicted the outcome of more than $70 \%$ of the 28,000 cases considered. ${ }^{10}$

In France, the possibility of using robotic programs in justice was included in the agenda for reforming the national judicial system. In the first phase, this will affect more than 2.5 million cases. ${ }^{11}$ At the same time, the introduction of digital technologies is accompanied by security measures of both technological and legal nature.

For example, France introduced criminal liability for using the results of the analysis of judicial practice, which makes it possible to predict what decision a particular judge might make in a case. Unlike the United States and the United Kingdom, where judges have accepted it as a fait accompli that AI law firms analyze their decisions down to the smallest detail and then create patterns of future behaviour, France has decided to stamp it out. ${ }^{12}$ The new article 33 of Law No. 2019-222 of 23 March 2019 on programming and reform of justice for 2018-2022 states that no personal data concerning judges or judicial clerks can be subjected to any kind of re-use for the purpose or as a result evaluating, analyzing or predicting their actual or perceived professional practice. ${ }^{13}$

Also, as digital technologies are introduced, questions periodically arise about the possible falsification of information during the investigation and trial of the case. If the investigator or the judge is dishonest, it is necessary to exclude the possibility of making certain changes and additions to the electronic document, both by establishing a ban on changing the electronic information used in proving the case, and by ensuring reliable protection of digital documents from possible modification.

The philosophy of ensuring a positive balance in terms of the introduction of these technologies and the possible costs of this process should be based on minimizing the risk of substitution of electronic data. This circumstance can be considered as a guarantee of ensuring justice in law en-

${ }_{10}$ Available at: http://www.sciencemag.org/news/2017/05/artificial-intelligence-prevails-predicting-supreme-court-decisions (accessed: 07.07.2020)

${ }_{11}$ Available at: https://www.humanite.fr/reforme-belloubet-des-logiciels-la-place-desjuges-mirage-de-la-justice-predictive-654139 (accessed: 07.07.2020)

12 Available at: https://www.artificiallawyer.com/2019/06/04/france-bans-judge-analytics-5-years-in-prison-for-rule-breakers/ (accessed: 07.07.2020)

13 Available at: https://www.legifrance.gouv.fr/eli/loi/2019/3/23/2019-222/jo/ article_33 (accessed: 07.07.2020) 
forcement in Russia, since the development of technologies is significantly ahead of the understanding of the moral and social consequences of their application. Therefore, one of the main tasks for modern lawyers will be to solve the problem of introducing into new systems of machine-readable law such algorithms that are able to assess the presence of a "spirit of law" (ie, ideas reflecting justice) in the text of a normative act.

For example, in 2018 the Council of Europe European Commission for the efficiency of justice (CEPEJ) for the first time adopted the document "European ethical Charter on the use of Artificial Intelligence in judicial systems and their environment" (hereinafter - the Charter), which establishes ethical principles concerning the use of AI in judicial systems and in the settlement of disputes: the principle of respect for fundamental rights; the principle of non-discrimination; the principle of quality and safety; the principle of transparency, impartiality and fairness; the principle of «under the control of the user». ${ }^{14}$

The development of an appropriate legal basis for the use of AI and the determination of the boundaries of automated information processing while maintaining the control of the decision by the judge, including the determination of grounds for refusing to execute it due to malfunctions, unauthorized external influences, etc., are necessary conditions to ensure the observance of human rights in the conditions for delegating the dispute resolution function to AI.

This means that already at the stage of software development, the norms prohibiting direct or indirect violations of fundamental values protected by the law of the national and international levels, including the Constitution of the Russian Federation, the Convention for the Protection of $\mathrm{Hu}-$ man Rights and Fundamental Freedoms and other international treaties should be fully integrated into domestic legislation. And given the ability of information technology to identify existing differences by grouping or classifying data pertaining to individuals or groups of individuals, the risks of replicating and exacerbating such discrimination should be prevented.

For example, Article 2 of the Charter states that discrimination can include perceived racial or ethnic origin, social origin, political opinion, religious or philosophical beliefs, trade union membership, genetic data, biometrics, health data, or data related to sexuality. When such discrimination is identified, consideration should be given to taking corrective measures

${ }^{14}$ European Ethical Charter on the Use of Artificial Intelligence in Judicial Systems and their environment adopted at the 31st plenary meeting of the CEPEJ. Strasbourg, 3-4 December 2018. 
to limit or, where possible, neutralizing these risks, and to raise interested participants' awareness.

The party must be informed that the final decision is binding, while preserving the right to access to justice, so that the case can be tried directly by a judge within the meaning of Article 6 of the European Convention.

In this regard, the requirements for maintaining control on the part of the judge, creating the ability to review automated decisions and providing access to the data array used for such automated resolution of the case are especially important.

\section{Conclusion}

The future of legal regulation related to the digitalization of judicial activity involves the development of two areas that require independent assessment. The first is the development of methods to simplify and speed up legal proceedings using information technologies as an analogue of traditional judicial actions, such as electronic court notice, electronic form of evidence, electronic court case, remote participation in court hearings, etc.

The second direction in the development of justice in the digital age, possessing significant potential, at the present stage requires the solution of a whole range of tasks, primarily related to ensuring fairness and security. Digital justice is not identical to the concept of electronic support for judicial activity, since involves not just changing the form of the process, but also essentially changing it by delegating the function of administering justice to digital technologies. This circumstance, on the one hand, requires the development and implementation of the category of fairness into machinereadable law, which implies the creation of special information and analytical software systems bound by the basic values of national and international law.

On the other hand, the introduction of these technologies should be accompanied by special security measures of both technological and legal nature, in particular, by creating an appropriate legal basis for defining the boundaries of automated information processing while preserving the possibility of revising the decision made by a judge, including determining the grounds for refusing its execution due to technical malfunctions, unauthorized external influences, etc.

In other words, regardless of the form and possible software solutions, the individual should be in the center of attention of the law enforcement system. And the use of digital technologies should be considered as a tool 
for achieving the goals of justice, which maximally helps to exclude the possibility of making an unjust decision in a case under the guise of compliance with the legal form.

Thus, the digitalization of justice is designed to further develop the principles of equality and adversarial processes recognized by the international community, facilitate access to justice, ensure its fairness and efficiency.

\section{I国 References}

Aletras N., Tsarapatsanis D., Preoțiuc-Pietro D. (2016) Predicting judicial decisions of the European Court of Human Rights: a natural language processing perspective. Peer Journal of Computer Science, no 2, p. 93.

Broomhall B. (2003) International Justice and the International Criminal Court: between Sovereignty and the Rule of Law. Oxford: Berg, 215 p. (in Russian)

Dutton Y. (2012) Virtual Witness Confrontation in Criminal Cases: A Proposal to Use Videoconferencing Technology in Maritime Piracy Trials. Vanderbilt Journal of Transnational Law, vol. 45, pp. 1283-1294.

Isaev I.A. (1994) A history of Russian state and law. Moscow: Jurist, 432 p. (in Russian)

Khabrieva T.Y., Chernogor N.N. (2018) The law in the conditions of digital reality. Zhurnal rossiyskogo prava, no 1, pp. 85-102 (in Russian)

Khabrieva T.Y., Lebedev V.M. (2019) Justice in modern world. Moscow: Kontrakt, 688 p. (in Russian)

Khazhipov R.H. (1990) The role of law and morality in the implementation of the essential forces of man. Candidate of Philosophical Sciences Thesis. Ufa, 186 p. (in Russian)

Kucherov I.I. (2017) Elements of the Financial Security and its Legal Support. Zhurnal rossiyskogo prava, no 6, pp. 69-79 (in Russian)

Kuzurmanova I.V. (2011) Administrative activities: system decomposition. Administrativnoe pravo i process, no 1, pp. 37-40 (in Russian)

Livshits R.Z. (1994) Theory of Law. Moscow: Juridicheskaya literatura, 224 p. (in Russian)

Maksyutin M.N. (2008) Theory of the jurisdictional process. Moscow: Prospekt, 224 p. (in Russian)

Medvedev R.F. (2018) The problems of legal regulation of digitalization under modern conditions. Zakonnost', no 9, pp. 14-15 (in Russian)

Pizzi W. (2019) Trials without truth: why our system of criminal trials has become an expensive failure and what we need to do to rebuild it. Moscow: Prospekt, 280 p. (in Russian) 
Povetkina N.A., Ledneva Y.V. (2018) Fintekh and Redtekh: Boundaries of Legal Regulation. Pravo. Zhurnal Vyssshey shkoly ekonomiki, no 2, pp. 46-67 (in Russian)

Reshetnyak V.I., Smagina E.S. (2017) Information technologies in civil proceedings (Russian and foreign experience). Moscow: Norma, $304 \mathrm{p}$. (in Russian)

Rudnev V., Pechegin D. (2020) Impact of leading digital technologies on criminal proceedings: case of video conferencing. 6th international conference on social, economic, and academic leadership. DOI: 10.2991/assehr.k.200526.047

Saksonov A.V. (2016) Right, the art of goodness and justice. Voprosy studencheskoi nauki, no 1, pp. 36-38 (in Russian)

Theory of criminal procedure: competitiveness (2013) N.A. Kolokolov (ed.). Moscow: Norma, 368 p. (in Russian)

Vekhov V.B. (2008) Fundamentals of forensic doctrine of the study and use of computer information and means of its processing. Volgograd: University press, 404 p. (in Russian) 